\title{
Pengembangan Nilai-Nilai Moral dan Agama pada Anak Usia Dini
}

\author{
Wardah Anggraini, Syafrimen Syafril \\ wardahanggraini@gmail.com,syafrimen@radenintan.ac.id \\ Universitas Islam Negeri Raden Intan Lampung, Indonesia
}

\begin{abstract}
Abstrak
Perkembangan nilai-nilai moral dan agama adalah kemampuan anak untuk bersikap dan bertingah laku. Islam telah mengajarkan nilai-nilai positif yang bermanfaat dalam kehidupan bermasyarakat. Hal ini menyebabkan perlunya pengembangan pembelajaran terkait nilai nilai moral dan agama. Hasil analisis menunjukkan bahwa dalam ajaran Islam telah dijelaskan bagaimana proses pengembangan nili-nilai agama dan moral pada anak usia dini dapat diterapkan dengan benar. Hasil analisis melalui pembahasan ditemukan 10 metode penting bagi pengembangan nilai-nilai moral dan agama pada anak usia 5 -6 tahun antara lain adalah (i) bercerita (ii) bernyanyi (iii) bersyair (iv) karyawisata (v)pembiasaan (vi) bermain (vii) outbond (viii)bermain peran (ix) diskusi dan (x) keteladanan. Temuan tersebut telah dibahas dengan berbagai konsep dan temuan-temuan sebelumnya.
\end{abstract}

Kata kunci : Nilai- nilai moral dan agama, Anak usia dini

\section{A. Pendahuluan}

Pengembangan moral agama sangat erat kaitannya dengan budi pekerti, sikap sopan santun, dan kemauan melaksanakan ajaran agama dalam kehidupan sehari-hari. Pembahasan filosofis yang di kemukakan oleh Kilpatrick pendidikan moral akan terus berkembang dengan berbagai pendapat pakar dalam aspek budi pekerti, nilai moral dan keagamaan. (William Kilpatrick, 1993). Lawrence Kholbergh lebih menekankan pendidikan moral diarahkan kepada tahap-tahap pembentukannya, sehingga pendidikan moral di dasarkan untuk membentuk setiap tahap-tahap peserta didik. Disamping tahapan perkembangan moralnya, Lawrence Kholbergh juga menawarkan konsep keadilan sebagai dasar pelaksanaan pendidikan moral di Barat. Prinsip tersebut merupakan suatu kondisi imanen dalam jaringan reasi social atau suatu hukum yang mengatur keseimbangan semua relasi social tersebut (Lawrence 
Khobergh, 2008). Oleh karena itu, Kholbergh memberikan cerita kepada orangorang yang memiliki umur yang berbeda dan budaya yang menempatkan seseorang dalam posisi dan situasi tertentu yang di konfrontaris dengan masalah moral dalam standar tertentu. Kholbergh kemudian menanyai orang-orang bagaimana mereka akan mengatasi masalah ini dan memberikan alasan serta solusinya. Piaget menyatakan bahwa anak anak berfikir dengan 2 cara yang sangat berbeda tentang moralitas tergantung pada kedewasaan perkembangan mereka. Piaget juga mengemukakan bahwa seorang manusia dalam kehidupannya akan mengalami rentangan perkembangan moral yaitu : a) tahap heteronomous yakni cara berfikir anak tentang keadilan peraturan yang bersifat objektif artinya tidak dapat diubah dan tidak dapat di tiadakan oleh manusia. b) dan tahap autonomous yaitu anak mulai menyadari adanya kebebasan untuk tidak sepenuhnya menerima aturan itu sebagai hal yang datang dari luar dirinya (Carpendale, Jeremy Im. Kohlberg and Piaget, 2000).

Menurut Kohlberg pengembangan dasar moral anak ( $\geq 10$ tahun) berada dalam pada fase pra konvensional yang di warnai dengan penalaran moral, anak menentukan keburukan perilaku berdasarkan tingkat hukuman dan akibat keburukan tersebut, sesangkan perilaku baik akan dihubungkan dengan pengindraan dari hukuman. Dan perilaku baik dihubungkan dengan pemuasan kinginan dan kebutuhan sendiri tanpa mempertimbangkan kebutuhan orang lain (William C Campbell, Frank J Cavico, Pedro F. Pellet, Bahaudin J. Mubtaja, 2010).

Menurut Syaodih menyatakan bahwa perkembangan nilai-nilai agama dan moral anak usia dini antara lain: anak besikap imitasi (imitation) yakni mulai menirukan sikap, cara pandang serta tingkah laku orang lain, anak bersikap inernalisasi yakni anak sudah mulai bergaul dengan lingkungan sosialnya dan mulai terpengaruh dengan keadaan di lingkungan tersebut, anak bersikap introvert dan ekstrovert yakni reaksi yang ditunjukkan anak berdasarkan pengalaman (Erma Purba, 2013). Menurut John Dewey, tahapan perkembangan moral sesorang berada pada fase pra konvensional yang memiliki karakteristik sikap dan perilaku anak dilandasi oleh implus biologis dan social ( Asti Inawati, 2017). Menurut pendapat para pakar dapat penulis simpulkan bahwa perkembangan moral dan agama anak usia 5-6 tahun adalah suatu kemampuan untuk berinteraksi dengan tingkah laku yang baik sesuai dengan norma-norma, sehingga menimbulkan perilaku yang baik dan buruk.

Perkembangan Nilai-Nilai Moral dan Agama. 
Menurut Kohlberg perkembangan moral anak usia prasekolah (paud) berada pada tingkatan yang paling dasar yang dinamakan dengan penalaran moral prakonvensional. Pada tingkatan ini anak belum menunjukkan internalisasi nilai-nilai moral (secara kokoh). Namun sebagian anak usia PAUD ada yang sudah memiliki kepekaan atau sensitivitas yang tinggi dalam merespon lingkungannya positif dan negative (Lawrence Kholbergh, 1979).

Dalam mengkaji perkembangan moral anak usia pra sekolah, Kohlberg memposisikan mereka pada level yang paling dasar, yaitu level 1 (moral prakonvensional). Pada tahap ini, anak melihat suatu kegiatan dianggap salah atau benar berdasarkan hukuman dan kepatuhan (punishment dan obedience orientation) serta individualisme dan orientasi tujuan instrumental (individualism and instrumental purpose). Pada tahap orientasi hukuman dan kepatuhan, suatu tindakan dinilai benar atau salah tergantung pada akibat dari kegiatan tersebut. Suatu kegiatan yang membuat ibu marah dianggap salah dan suatu kegiatan yang membuat ibu senang dianggap baik atau benar (lawrence Kholbergh, 1975).

Ketika Kohlberg menyatakan bahwa moralitas diperoleh melalui tahap-tahap perkembangan, dia menggunakan konsep tahap dalam suatu cara formal. Kohlberg menjelaskan bahwa 1) setiap tahap memiliki jenis pemikiran moral yang berbeda, bukan hanya peningkatan pemahaman konsep moralitas; 2) tahap-tahap tersebut terjadi dalam urutan langkah yang sama, sehingga tidak ada loncatan atau langkah mundur ke belakang; dan 3) tahap-tahap merupakan prepotent (Colby Ann, Larence Kholbegh, 1987). Hal tersebut berarti anak-anak memahami semua tahap yang ada dibawah mereka dan barangkali memiliki pemahaman yang tidak lebih banyak dari orang yang ada di atasnya. Anak tidak dapat memahami tahap yang lebih tinggi, tanpa memperhatikan dorongan, pembelajaran dan latihan. Kohlberg juga mengatakan bahwa tahap-tahap tersebut bersifat universal dan terjadi dalam cara yang sama, tanpa memperhatikan perbedaan individu dalam pengalaman dan budaya. Hal yang penting dari teori Kohlberg adalah bahwa tingkat penalaran moral akan meningkat seiring dengan usia seseorang (Lawrence Kholbergh 1975).

Selanjutnya Piaget menyatakan perkembangan moral terjadi dalam dua tahapan yang jelas. Tahap pertama disebut tahap realism moral atau moralitas oleh pembatasan, kemudian tahap kedua disebut tahap moralitas otonomi atau moralitas kerja sama atau hubungan timbal balik. Anak usia 5-6 tahun berada pada tahap pertama yaitu tahap realisme moral (5-7 tahun). Pada tahap ini perilaku anak ditentukan oleh ketaatan otomatis terhadap peraturan tanpa penalaran atau penilaian. 
Mereka menganggap bahwa orang tua dan semua orang dewasa berwenang dan membuat peraturan, dan mereka harus mengikuti aturan yang diberikan tersebut tanpa mempertanyakan kebenarannya ( Sigmund Freud, 1996). Dalam tahap ini, anak memilai suatu perbuatan itu benar atau salah berdasarkan konsekuensi dari perbuatan tersebut, bukan karena motivasi yang melatarbelakangi perbuatan tersebut. Sebagai contoh: suatu tindakan dianggap "salah" karena mengakibatkan hukuman dari orang lain.

Teori psikoanalisis Freud menjelaskan bahwa perkembangan sosio-moral berjalan seiring dengan perkembangan seksualitas. Menurut teori ini terdapat beberapa fase perkembangan moral dengan penggolongan usia tertentu pada setiap fase. Berdasarkan penggolongan usia tersebut, anak usia 5-6 tahun berada pada fase phalis (4-6 tahun). Pada fase ini anak mendapat kepuasan dari suatu yang menyentuh alat kelaminnya. Melalui kegiatan bermain anak mulai membangun hubungan-hubungan sosial yang diferensial, berdasarkan perbedaan jenis kelamin. Hubungan sosial yang berbasis perbedaan jenis kelamin ini juga mempunyai peran penting terhadap perkembangan kesadaran moral (Sigmund Freud, 1996).

Terkait tentang perkembangan nilai agama dan moral anak usia dini, Suyadi menjelaskan perkembangan nilai-nilai moral-keagamaan pada anak usia 5-6 tahun yaitu: Mampu menghafal beberapa surah dalam Al-Qur"an, seperti AlIkhlas, dan An-Naas, mampu menghafal gerakan shalat secara sempurna, mampu menyebutkan beberapa sifat Allah, menghormati orang tua, menghargai teman-temannya, dan menyayangi adik-adiknya atau anak dibawah usianya, dan mengucapkan syukur dan terima kasih ( Suyadi, 2010).

\section{B. Pengembangan Nilia-nilai Moral dan Agama}

Pengembangan nilai nilai moral dan agama anak dapat dikembangkan melalui metode sebagai berikut :

\section{(i) Metode bercerita}

Metode Bercerita dapat dijadikan metode untuk menyampaikan nilai-nilai yang berlaku dalam masyarakat. Dalam cerita atau dongeng dapat ditanamkan berbagai macam nilai moral, nilai agama, nilai sosial, nilai budaya, dan sebagainya. Ketika 
bercerita seorang guru juga dapat menggunakan alat peraga untuk mengatasi keterbatasan anak yang belum mampu berpikir secara abstrak (Zainab, 2012).

(ii) Metode bernyanyi

Metode Bernyanyi adalah suatu pendekatan pembelajaran secara nyata yang mampu membuat anak senang dan bergembira. Anak diarahkan pada situasi dan kondisi psikis untuk membangun jiwa yang bahagia, senang menikmati keindahan, mengembangkan rasa melalui ungkapan kata dan nada. Pesan-pesan pendidikan berupa nilai dan moral yang dikenal- kan kepada anak tentunya tidak mudah untuk diterima dan dipahami secara baik. Anak tidak dapat disamakan dengan orang dewasa (sabiati Amin 2016).

\section{(iii) Metode bersyair}

Pendekatan pembelajaran melalui kegiatan membaca sajak merupakan salah satu kegiatan yang akan menimbulkan rasa senang, gembira, dan bahagia pada diri anak. Secara psikologis anak Taman Kanak-kanak sangat haus dengan dorongan rasa ingin tahu, ingin mencoba segala sesuatu, dan ingin melaku- kan sesuatu yang belum pernah dialami atau dilakukannya. Melalui metode sajak guru bisa menanamkan nilainilai moral kepada anak. Sajak merupakan metode yang juga dapat membuat anak merasa senang, gembira dan bahagia ( Arief Armai, 2011)

(iv) Metode karyawsata

Metode ini bertujuan untuk mengembangkan aspek perkembangan anak Taman Kanak-kanak yang sesuai dengan kebutuhannya. Tujuan berkarya wisata ini perlu dihubungkan dengan tema-tema yang sesuai dengan pengembangan aspek perkembangan anak Taman Kanak- kanak. Tema yang sesuai seperti: binatang, pekerjaan, kehidupan kota atau desa, pesisir, dan pegunungan ( Mahyumi Natina, 2012)

(v) Metode pembiasaan

Metode Pembiasaan terkait dengan penanaman moral, lebih banyak dilakukan melalui pembiasaan-pembiasaan tingkah laku dalam proses pembelajaran. Ini dapat dilihat misalnya, pada berdoa sebelum dan sesudah belajar, berdoa sebelum makan 
dan minum, mengucap salam kepada guru dan teman, merapikan mainan setelah belajar, berbaris sebelum masuk kelas dan sebagainya ( Ayi Olim, 2010 )

\section{(vi) Metode bermain}

Metode Bermain ternyata banyak sekali terkandung nilai moral, diantaranya mau mengalah, kerjasama, tolong menolong, budaya antri dan menghormati teman. Nilai moral mau mengalah terjadi manakala siswa mau mengalah terhadap teman lainnya yang lebih membutuhkan untuk satu jenis mainan. Pengertian dan pemahaman terhadap nilai moral mau menerima kekalahan atau mengalah adalah salah satu hal yang harus ditanamkan sejak dini ( Rozalena, 2017).

\section{(vii) Metode outbond}

Metode Outbond merupakan suatu kegiatan yang me-mungkinkan anak untuk bersatu dengan alam. Melalui kegiatan outbond siswa akan dengan leluasa menikmati segala bentuk tanaman, hewan, dan mahluk ciptaan Allah yang lain. Cara ini dilakukan agar anak tidak hanya memahami apa yang diceritakan atau dituturkan oleh guru atau pendidik di dalam kelas. Melainkan mereka diajak langsung melihat atau memperhatikan sesuatu yang sebelumnya pernah diceritakan di dalam kelas, sehingga apa yang terjadi di kelas akan ada sinkronisasi dengan apa yang tampak di lapangan atau alam terbuka (Yunaida, Hana; Rosita, Tita, 2018 )

(viii) Metode bermain peran

Metode ini merupakan salah satu metode yang digunakan dlam menanamkan nilai nilai moral ke pada anak TK. Dengan bermain peran anak akan mempunyai ksadaran merasakana jika ia menjadi seseorang yang dia perankan dalam kegiatan bermain peran ( Vivit Risnawati, 2012)

\section{(ix) Metode diskusi}

Metode ini adalah metode utuk mendiskusikan tentang suatu peristiwa. Biasanya dilakukan dengan cara siswa diminta untuk memperhatikan sebuah tayangan dari CD, kemudian setelah selesai siswa diajak berdidskusi tentang tayangan tersebut. Isi diskusinya antara lsin mengapa hal tersebut dilakukan, mengapa anak itu dikatakan baik, mengapa harus menyanyangi dan sebaginya ( Sapendi, 2015). 


\section{(x) Metode keteladanan}

Menurut Cheppy Cahyono, guru moral ideal adalah yang dapat menempatkan dirinya sebagai fasilitator, pemimpin, orangtua dan bahkan tempat menyandarkan kepercayaan, serta membantu orag lain dalam melakukan refleksi ( Cahyatun Mchsunah, 2017)

\section{Kesimpulan}

Anak adalah generasi penerus keluarga dan bangsa yang perlu mendapat pendidikan yang baik sehingga potensi-potensi dirinya dapat berkembang dengan pesat, sehingga akan tumbuh menjadi manusia yang memiliki kepribadian yang tangguh dan cakap serta terampil. Oleh karena itu penting bagi lembaga dan keluarga untuk berperan dan bertanggungjawab dalam memberikan berbagai macam stimulasi dan bimbingan yang tepat sehingga akan tercipta gereasi penerus yang berakhlak dan bertingkah laku yang sesuai dengan norma. Pengembangan nilai-nilai moral dan agama anak usia 5-6 tahun bias dilakukan dengan berbagai macam metode antara lain : bernyanyi, bermain, kayawisata, outbond, bermain peran, bercerita, bersyair dan keteladanan.

\section{Rujukan}

Asti Inawati. 2017. Strategi Pengembangan Moral dan Nilai Agama Untu Anak Usia Dini, Jurnal Pendidikan Anak, Vol. 3 No. 1

Colby, Ann; Kohlberg, Lawrence. 1987. The Measurement Of Moral Judgement: Volume 2, Standard Issue Scoring Manual. Cambridge University Press.

Erna Purba. 2013. Peningkatan Nilai-Nilai Agama Dan Moral Melalui Metode Bercerita Pada Anak Usia 4-6 Tahun, Pg-Paud Fkip Universitas Tanjungpura Pontianak.

Hakim, Lukman. 2012. Internalisasi Nilai-Nilai Agama Islam Dalam Pembentukan Sikap Dan Perilaku Siswa Sekolah Dasar Islam Terpadu Al-Muttaqin Kota Tasikmalaya. Jurnal Pendidikan Agama Islam-Ta'lim, Vol.10 No.1

Kilpatrick, William. 1993. Why Johnny can't tell right from wrong: And what we can do about it. Simon and Schuster.

Lawrence Kholbergh. 1975. The cognitive-developmental approach to moral education. The Phi Delta Kappan, Vol.56 No.10

Lawrence Kholbergh. 1979. The claim to moral adequacy of a highest stage of moral judgment. The journal of philosophy, Vol.70 No.18 
Lawrence Kohlberg ; Richard H Hersh. 2010. “ Moral Development : a Review of the theory", Theory into Practice, Vol. 16, No. 2

Machsunah, Yayuk Chayatun. 2017. Penanaman Pendidikan Karakter Melalui Keteladanan Pendidik (Studi Kasus Di Lbb Taman Pintar: Sahabat Sekolah Anak Lamongan). Journal Stkip Pgri Lamongan, Vol.1 No.2

Nuryanto, Sidik. 2017. Peningkatan Nilai-Nilai Karakter Dengan Metode Mendongeng Cas Cis Cus Di BA Aisyiyah Kaponan 2 Ponorogo. Journal Of Nonformal Education, Vol. 3 No. 1

Risnawati, Vivit. 2012. Optimalisasi Pendidikan Karakter Anak Usia Dini Melalui Sentra Main Peran Taman Kanak-Kanak Padang. Jurnal Pesona Paud, Vol.1.No. 2

Sabi'ati, Amin. 2016. Membangun Karakter Aud Dalam Pengembangan Nilai Agama Dan Moral Di Ra Masyithoh Pabelan Kab. Semarang. Al-Athfal: Jurnal Pendidikan Anak, , Vol.2 No.4

Sapendi, Sapendi. 2015. Internalisasi Nilai-Nilai Moral Agama Pada Anak Usia Dini. At-Turats, Vol. 9. No. 2

Sigmund Freud. 1996. Observations On Transference-Love: Further Recommendations On The Technique Of Psycho-Analysis III. The Journal of psychotherapy practice and research, , Vol.2 No.2

Suyadi. 2010. Psikologi Belajar Anak Usia Dini, (Yogyakarta : Pt Pustaka Aadani)

William C Campbell, Frank J Cavico, Pedro F. Pellet, Bahaudin J. Mubtaja,. 2010. Applying Moral Development Literature And Aethnical Theories To Administration of Taxes In Kosovo, Internasional Business and Economics Research Journal, Vol. 9, No. 7

Yunaida, Hana; Rosita, Tita. 2018. Outbound Berbasis Karakter Sebagai Media Pembelajaran Anak Usia Dini. Comm-Edu (Community Education Journal), Vo. 1 No.1

Zainab, Zainab. 2012. Peningkatan Perkembangan Moral Anak Melalui Metode Cerita Bergambar Tk Lembah Sari Agam. Jurnal Pesona Paud, Vol 1. No.03 
